\title{
CONFLITO ENTRE O PRINCÍPIO DA DIGNIDADE DA PESSOA HUMANA VERSUS PRINCÍPIO DA EXISTÊNCIA DO PRÉ-CUSTEIO DA SEGURIDADE SOCIAL: UMA ANÁLISE DE TERCEIRIZADOS ANÁLOGOS SOB A "FÓRMULA PESO" DE ROBERT ALEXY
}

\author{
Jurandir Pereira da Silva Filho ${ }^{1}$
}

\section{RESUMO}

O presente artigo visa abordar um caso prático onde idosos terceirizados rurais em situação análogas ao trabalho escravo são resgatados, o desafio maior é como um juiz a quo deveria aplicar a fórmula peso do Robert Alexy, filósofo alemão, pai da Teoria dos Direitos Fundamentais. Há um eminente confronto entre dois princípios basilares, de um lado a dignidade da pessoa humana, do outro, pré-custeio, sustento fundamental da nossa Seguridade Social, contudo, um deles deve ser afastado e o outro aplicado em sua totalidade, sem um prejudicar o outro.

Palavras-chave: Princípio da Dignidade da Pessoa Humana; Robert Alexy; Fórmula Peso; Princípio da Pré-Existência do Custeio

\section{CONFLICT BETWEEN THE PRINCIPLE OF DIGNITY OF THE HUMAN PERSON VERSUS THE EXISTENCE OF SOCIAL SECURITY PRE-COST: AN ANALYSIS OF ANALOGUE THIRD PARTIES UNDER THE "FORMULA WEIGHT" OF ROBERT ALEXY}

\begin{abstract}
This article aims to address a practical case where rural outsourced elderly in situations analogous to slave labor are rescued; the greatest challenge is how a judge a quo should apply the weight formula of Robert Alexy, German philosopher, father of Fundamental Rights Theory. There is an eminent confrontation between two basic principles, on the one hand the dignity of the human person, on the other, pre-costing, fundamental sustenance of our Social Security, however, one must be removed and the other applied in its totality, without the other.
\end{abstract}

Keywords: Principle of Dignity of the Human Person; Robert Alexy; Weight Formula; Principle of Pre-Existence of Costing

\subsection{INTRODUÇÃO}

A presente obra é um estudo de caso, intitulado 'Conflito entre o Princípio da Dignidade da Pessoa Humana versus Princípio da existência do pré-custeio da seguridade social: Uma análise de terceirizados análogos à escravo sob a "fórmula

\footnotetext{
${ }^{1}$ Advogado Trabalhista e Previdenciarista. Graduado em Direito pelo IESP e Pós- Graduado em Direito Processual Civil pela Anhanguera-Uniderp.
} 
peso" de Robert Alexy'. O mesmo pretende ser apresentado na linha de pesquisa Direitos sociais, seguridade e previdência social.

Alexy é um filosofo alemão contemporâneo que em 1984 foi habilitado como o pai da Teoria dos Direitos Fundamentais, dividido em dois clássicos da Filosofia e Teoria do Direito. Professor da Universidade de Kiel é um misto normativo de Kelsen (positivismo jurídico), com bases jurisprudenciais de Aristóteles, Kant, Frege além de ser influenciado em grandes moldes por Hart e Kelsen. Ensinou o mundo a respeita-lo pela forma que soluciona conflitos entre princípios em uma fórmula peso impressionante - Um misto de intensidade e soluções ponderadas, objetivando evitar contradições -.

Para selecionar essa aplicabilidade, trago um meio ambiente do trabalho um tanto desafiador, em um caso prático dedutivo, onde abordo a questão de idosos terceirizados rurais em situação análogas ao trabalho escravo, observando como um juiz deve decidir o caso delicado aplicando a fórmula peso do referido autor.

Passo ainda por bases conceituais para que seja entendido todo deslinde desde os primórdios, com bases dos institutos oficiais brasileiros.

O objeto desse artigo é apresenta a sociedade como os direitos fundamentais, principalmente da dignidade da pessoa humana deve ser respeitada, em uma década já marcada por reformas governamentais, globalização e capitalismo em cima dos mais necessitados.

O objetivo é mostrar os princípios e valores sociais se escondem atrás das jurisprudências; Esses, essenciais para efetivação de direitos básicos, trazendo uma visão simples de suas aplicações quando confrontados.

A metodologia é argumentativa do autor, além do método racional pragmático processual, em razão dos direitos fundamentais em relação à sua aplicabilidade ao fato real e dedutivo à sua aplicação final.

$\mathrm{Na}$ esfera dos dados, trago o Departamento Intersindical de Estatísticas e Estudos Socioeconômicos (DIEESE) entre os anos de 2010 à 2013 fez um levantamento no Brasil com números alarmantes: Dos 3.553 trabalhadores resgatados em situação 
análoga à escravidão, 3.000 eram terceirizados nas 10 principais operações. Com esses dados, somando à um caso prático, onde havia pessoas idosas com doenças ocupacionais que já deveriam gozar de sua aposentadoria e não tiveram seus proventos recolhidos por anos, ou seja, não houve um prévio custeio. Há um confronto claro entre a previdência alegando que sem a carência e o custeio não seria possível conceder, pois abriria precedentes para outros casos, lesando o Estado. Do outro lado, às partes alegam que não conseguiriam custear pela situação análoga e presam pelo princípio da Dignidade da Pessoa Humana.

Por fim, resumo que o artigo visa trazer uma solução, observando o peso abstrato (relevância), grau de interferência dos princípios (cumprir os princípios) e evidência (diante do confronto, quem teria maior ou menor evidência) segundo Robert Alexy. Em suma, os pesos seriam aplicados por um juiz no caso prático: Aplicando a "fórmula peso" do Robert Alexy poderia aposenta-los desconsiderando o princípio do pré-custeio e aplicando apenas o princípio da dignidade da pessoa humana?

\subsection{DADOS DIEESE E A REALIDADE DA TERCEIRIZAÇÃO}

O Departamento Intersindical de Estatísticas e Estudos Socioeconômicos ${ }^{2}$ entre os anos de 2010 e 2013 fez um estudo minucioso sobre os terceirizados no nosso país com às profissões que mais possuíam uma mão de obra terceirizadas e fez alguma revelações surpreendentes, na parte de serviços elétricos por exemplo, de 61 terceirizados perderam suas vidas contra 18 de empregados diretos (CLT), os que trabalhavam em construções de edifícios, de 75 falecimento eram de terceirizados no total de 135 morte. Já em 2014 o Departamento apontou uma rotatividade maior em empregos, gerando uma maior base de auxílios desempregos, pois o tempo médio dos contratos que antes era de 34,1 meses ( 2 anos e 10 meses), enquanto que em 2010 com uma maior rigidez na terceirização, esse período era de 70,3 meses (5 anos e 10 meses). O DIEESE ainda concluiu que nesse mesmo período, a operação de resgate dos trabalhadores em situação análoga à escravidão de 3.553 casos, quase 3.000 eram terceirizados, acentuando-se o ano de 2013. 
Tudo isso tende agravar, gerando prejuízos para os trabalhadores, para o sistema da Seguridade Social, pois terão mais trabalhadores doentes e acidentados. Para a Previdência Social ainda haverá uma diminuição dos recolhimentos mensais pela diminuição da renda advinda do trabalho, uma vez que o recolhimento seria falho. A solução é que quando bem fiscalizado, por meio jurídico, invocasse a instruções normativas dos superiores tribunais para que termos o prévio bloqueio via BACENJUD para uma efetivação do mínimo de custeio para previdência, recolhendo os tributos previdenciários devidos.

\subsection{DUMPING SOCIAL, UM BRAÇO DA TERCEIRIZAÇÃO}

A Juíza do trabalho e pesquisadora da RENAPEDTS - Rede Nacional de Pesquisa e Estudos em Direito do Trabalho e Previdência Social, Valdete Souto Severo, no seu recente artigo Terceirização, Dumping Social e Direito do trabalho: Compreendendo os riscos da lógica liberal e retomando os rumos da legis. social ${ }^{3}$ alude há um link muito interessante de como essa realidade é presente nos dias atuais, explicando claramente que o dumping social pode ser uma prática reiterada do descumprimento não só da legislação trabalhista, mas de todo conjunto social, um verdadeiro desrespeito às normas vigentes para que cresçam no mercado um tanto acirrado.

Essa prática nasceu nos países do Hemisfério Norte, com um significa livre de lixo - Sobretudo sobre aqueles países destruídos pela guerra - Pois necessitam se refazer diante do comércio internacional, rebaixando assim com essa prática a qualidade de vida dos trabalhadores, direitos sociais e o principal, uma vantagem econômica sobre aqueles empregadores que cumpriam às obrigações jurídicas jus laborativas de cada funcionário.

Aliado a isso, e vinculado ao nosso tema, os trabalhos análogos ao escravo começaram de certo modo abrir grandes escalas no mundo, ganhando forças depois em países como China (Eletrônicos), Filipinas e Espanha (Vestuários) - Implementando uma cultura nos empresários mundiais que esses países mesmo com economia enfraquecida, tinham uma "super vantagem competitiva" -. Na prática, quando vemos 
alguns dados anuais de pesquisa, observamos que o dumping aliado a terceirização, pois ambos são subsequentes, há uma tática mascarada de insegurança diante da perda dos postos de trabalho; Trabalhadores já conformados à inexistência de qualquer garantia trabalhista, como gozo de descansos (anuais principalmente) e quanto a dignidade humana, uma verdadeira ausência de pertencimento ao ambiente de trabalho, pois não teriam autoestima de levantar a cabeça, nem vozes para aqueles que no raciocínio lógico boicotam o sistema constitucional do pleno emprego e ainda do primado valor social do trabalho.

E mais, quando descobrimos que no final, sem surpresas, a tomadora dos serviços é na realidade a empregadora da força de trabalho, ou seja, aquela que faz dumping e a terceirização, que deveria ser apenas solidária em diversos aspectos nada mais é, que a principal no meio 'sugatório'.

Quando partimos para condenação desses abusos que resultam em trabalho análogos, terceirização, o dumping social entra em fase de esquecimento e difícil de quantificar nas esferas jurídicas nacionais, principalmente na forma incidental. $\mathrm{Na}$ racionalidade liberal, a autora destaca por exemplo que a mentalidade burguesa ainda é determinante em nosso modo de aplicar o Direito, até mesmo por seu caráter genético de forma jurídica para permitir que um tipo especifico de sociedade (capitalista) se desenvolva. De modo que ainda iremos galgar muito para um bom reconhecimento do dumping social.

\subsection{O DANO EXISTENCIAL NA JORNADA EXCESSIVA, UMA ANALOGIA AO TRABALHO ESCRAVO}

Continuando a falar de ideias e raciocínios liberais, a nova reforma traz uma imensa dificuldade quanto ao dano e suas vertigens no tocante a jornada excessiva de trabalho, que beira muitas vezes em uma jornada quase análoga. Irei descrever nesse tópico, lineares conceituais em sua caracterização, uma outra opção um Juiz a quo poderia tomar no caso concreto. 
Como juristas, inicialmente podemos ver o dano como violação à um interesse pessoal de liberdade e constitucionalmente protegido. No campo trabalhista, o dano é aquilo que o empregado é violado de forma que prejudiquem sua vida pessoal, e excessivo quando frustram os seus poderes vitais jus laborativos, em resumo, aquilo que não colabora para uma boa-saúde psíquica e física.

O professor peruano Carlos Fernandez Sessarego em publicação na revista Foro Jurídico - Pela Faculdad de Derecho de la Ponticia Católica del Perú ${ }^{4}$ em 2003, defendeu que os danos dos projetos de vida da pessoa é a não implicância de certeza, podendo ter consequências em três tríades da vida cotidiana:

Intensidade - Aqui se concentra a frustação inicial da vida pessoal, de forma parcial ao cumprimento de projetos. É um começo da auto sabotagem com elevadas doses de baixa-estima.

Consequência - Um retardo na realização dos projetos em níveis rápidos na escala dos sonhos futuros.

Magnitude - A junção da intensidade e consequência se origina a frustação total e o consequente reflexo psíquico e físico nos trabalhadores. Sendo algo in re ipsa na violação dos direitos fundamentais.

Em cunho histórico, o dano tomou forma a partir da segunda Constituição italiana em 1948, reconhecendo que além do dano criminal, haveria outras vertentes das violações constitucionais, como o direito a saúde, batizados incialmente como danos biológicos, no qual se caracterizou mais a frente como dano existencial, pelo fato de envolver o sujeito, aspectos da vida social e familiar.

Visto ainda, níveis detectáveis pelo sofrimento em atividades profissionais que resplandeciam na vida pessoal, de modo que sua principal característica era o 'não fazer' ou 'não conseguir' fazer projetos da vida pessoal (perturbamento dell' 'agenda).

Nacionalmente, esse gancho é muito bem explanado pelo Júlio César Bebber em seu artigo Danos Extrapatrimoniais (estético, biológico e existencial) - breves considerações $^{5}$ publicado na revista LTR em 2009, quando descreve que no Brasil a sua recepção continuou como um Dano Existencial, existencial pelo fato de que o seu 
impacto provoca um vazio existencial no homem que perde sua gratificação vital por projetos.

Sônia Mascaro Nascimento ${ }^{6}$ igualmente o reconhece e adiciona que tudo isso advém da relação ilegal patronal de modo que não deixa o trabalhador mais se autodeterminar, cita-se como exemplo: Direito ao lazer $\left(\operatorname{art} .6^{\circ}\right)$, acesso à educação fora do horário de trabalho (art.205), acesso à cultura em seus momentos de lazer (art.215), realização de atividades desportivas (art.217) e convivência familiar (art. 227 e 229), uma questão sempre colocada em cheque e sempre nos remete a isso é a jornada excessiva de trabalho, que mesmo estabelecido o sistema de prorrogação e compensação de jornada, é onde os órgãos fiscalizatórios esbarram e condenam, pois passam das 11, 12, 13 horas fácil, principalmente os trabalhadores rurais no qual não possuem instruções e seus mandatários alegam que os mesmos estendem sua jornada por força maior (na lavoura, em épocas de pré-chuva ou na temporada de colheita/plantio).

Contudo, de forma continua, esquecendo que por 'força maior' é no máximo 45 dias anuais como descreve a carta superior trabalhista, e então entra não só a aplicação do dano existencial por desse critério horizontal, pois ceifa o convívio familiar e apresenta um cansaço excessivo nos trabalhadores, mas também uma característica fácil de trabalho análogo ao escravo.

O entorse no recolho previdenciário fica totalmente comprometido, uma vez que há desconto de férias quando os juízes não trabalhistas e apenas federais, por esquecimento ou falta de ajustes, não afastam 'pontos piradas' (britânico). É uma prática integrada dos grandes empresários nacionais: Dumping Social e o desdobramento para o Dano Existencial. É preciso avanços humanitários em um judiciário.

\subsection{O TRABALHO ESCRAVO MUNDO-BRASIL}

Devemos imaginar que a escravidão é tão antiga quanto a humanidade na terra, pois é quase impossível não reconhecermos que enquanto homens queremos utilizar o 
trabalho do semelhante para satisfazer nossas necessidades de sobrevivência; o homem nasce, cresce, descobre o trabalho alheio e fica rico já dizia o ditado popular;

No meio ambiente laboral, vemos que ao longo do tempo essa exploração só é racional com suas devidas pausas físicas e psíquicas e uma contraprestação em pecúnia; caso contrário, seria uma forma de trabalho forçado ou compulsório - todo trabalho ou serviço de uma pessoa sob ameaça de sanção, no qual ela não se ofereceu espontaneamente - e nesse caso, a Organização Mundial do Trabalho (OIT) nas suas Convenções ns.29 e 105 de 1930 pedem veementemente sua eliminação, no qual o nosso país é signatário.

Elisaide Trevisan, em Trabalho escravo no Brasil contemporâneo. Entre as presas da clandestinidade e as garras da exclusão $(2015)^{7}$ deixa claro que a escravidão faz-se presente na atualidade em escala mundial, sendo uma nobre particularidade dos países em desenvolvimento, pois estão na plena ascensão da economia capitalista refletindo sobretudo em escala global na dignidade da pessoa humana.

No Brasil, o brilhante autor Julpiano Chaves Cortez em Trabalho escravo no contrato de emprego e os direitos fundamentais $(2014)^{8}$ confirma que já sabíamos, o trabalho forçado ou escravo no nosso país se dá pela servidão de dividas, coagido pelo patrão moral ou física justificado por esse possível débito, enraizando ainda o trabalhador que se localiza em lugares ermos, fica obrigado a adquirir suplementos básicos (mercadorias) em lojas e armazéns apenas do empregador com preços elevados (truck system ou 'sistema de barracão') tornando a dívida quase impossível de ser paga e o mesmo ficando sempre no emprego com a esperança que um dia pague tudo.

A partir disso, vem o processo a restrição de locomoção, restringindo o ir e vir, consequente quebrando do princípio da dignidade da pessoa humana; cria-se o cárcere, tipificado no código penal. Criando o círculo já citado das jornadas exaustivas em condições degradantes com restrição da autodeterminação do trabalho.

A autora Isabela Parelli Haddad Flaitt, contrapõe em $O$ trabalho escravo à luz ds Convenções ns.29 e 105 da organização internacional do trabalho ${ }^{9}$ cita que trabalho degradante é outra vertente, pois não há falta de liberdade do trabalhador, mas sim por falta de opção do obreiro e não por livre e espontânea vontade, seja por morar em localidade com alto índice de desemprego ou melhores condições de dignidade, 
havendo algo parecido com voluntariedade por parte do trabalhador, mas verdadeiramente uma condição indigna e aviltantes do labor, onde o empregado a qualquer momento ou buscando algo melhor, pode sair. É importante temos às duas visões para um enriquecimento laboral. Ainda assim, acredito que é apenas uma diferenciação apenas de nomenclatura.

Por fim, como condição penal, é versado no artigo 149 do código penal brasileiro como vemos a seguir:

Art. 149. Reduzir alguém a condição análoga à de escravo, quer submetendo-o a trabalhos forçados ou à jornada exaustiva, quer sujeitando-o a condições degradantes de trabalho, quer restringindo, por qualquer meio, sua locomoção em razão de dívida contraída com o empregador ou preposto:

Pena - reclusão de dois a oito anos, e multa, além da pena correspondente à violência.

$\S 1^{\circ}-$ Nas mesmas penas incorre quem:

I - Cerceia o uso de qualquer meio de transporte por parte do trabalhador, com o fim de retê-lo no local de trabalho;

II - mantém vigilância ostensiva no local de trabalho ou se apodera de documento ou de objetos pessoais do trabalhador, com o fim de retê-lo no local de trabalho.

$\S 2^{\circ}$ - A pena é aumentada de metade, se o crime é cometido:

I - contra criança ou adolescente;

II - por motivo de preconceito de raça, cor, etnia, religião ou origem.

Com isso, podemos afirmar que o trabalho análogo ao escravo é gênero; Uma espécie do trabalho forçado ou degradante como preferem por nomenclatura.

\subsection{FISCALIZAÇÃO MINISTÉRIO PÚBliCO DO TRABALHO - DADOS ATUALIZADOS}


Com certeza se o poder fiscalizatório do empregador fosse exercido dentro da lei, onde é entendido quando o mesmo assume o risco de empreender, como versa o artigo $2^{\circ}$ da CLT, entendendo-se que junto vêm todo recolhimento previdenciário legal, o número de empregos mantidos, meio ambiente do trabalho, dentre outros mecanismos do bem estar social, teríamos um outro Brasil.

Todavia, os números mostram um outro país, uma vez que criou-se um dogma empresarial que ao assinar uma CTPS torna atividade econômica mais volátil ao fracasso pelos altos custos tributários.

Entendimento isso, em um mundo paralelo joga-se contra o trabalhador situações adversas e descobertas legalmente, começando com uma margem para o trabalho análogo ao escravo, pois uma vez que o obreiro se submete às situações sem recolhimentos legais, mais a frente é quase certo que terá abusos nas esferas salarias e condições de trabalho degradantes.

Em números recentes, divulgados em 17 de Janeiro de 2018 pelo portal G1 ${ }^{10}$ com base de dados do Ministério do Trabalho, o número de erradicação de trabalho escravo caiu 23,5\% em 2017 comparado a 2016 (88 fiscalizações, contra 175 em 2016) uma diminuição latente ainda quando compara ao número de resgatados, apenas 341 (menor desde 1998 - 159 casos) e em relação a 2016, quando foram resgatados 885 trabalhadores, a redução gira em torno de 61,5\% - Sendo que de 2001 a 2015 esses números passavam de 1 mil resgatados.

Quando confrontado o Ministério do Trabalho alega alguns fatores ${ }^{11}$ :

1) Que os resgates do trabalhos análogos são baseados em denúncias;

2) Corte orçamentário no ano de 2017 nas atividades rotineiras de fiscalização;

3) Mudança do comportamento do empresariado, onde na maioria das operações são encontrados apenas 40 trabalhos e uma mudança para contratos curtos, o que dificulta às operações. Pois muitos giram em torno de contratos intermitentes;

4) Portaria Governamental (lista suja $-n^{o}$ 1.129) alterando conceitos, qualificações e condições para atender e identificar requisitos do trabalho 
escravo, de cunho mais político e menos efetivo, portaria essa que durou alguns meses mas de crucial perda nas operações.

Com a ministra Rosa Weber, por meio do STF suspendendo a portaria, espera-se que o Ministério Público do Trabalho retorne efetivamente suas operações.

\subsection{DOUTRINA por ROBERT ALEXY}

Segundo o Prof. Dr. Phd. hc. Robert Alexy, em sua obra Dignidade Humana, Direitos Sociais e Não-positivismo inclusivo devemos entender primeiro a relatividade ${ }^{12}$ da Dignidade Humana ou o seu absolutismo, onde nesse último o conceito de dignidade é considerado uma norma, que em outras palavras é considerada regra, que exige algo determinado para exercer o comandos definitivo.

O exemplo clássico que vemos a seguir, é a impossibilitando aplicar uma proporcionalidade sobre elas, sob pairando sobre qualquer princípio que viesse confrontá-la; já em caráter relativo, a dignidade seria preponderada pelo fato de não ser respeitada como algo maior, uma vez que violada em caso concreto, seria aplicado por exemplo os mandamentos do princípio da proporcionalidade.

No caso objeto desse artigo, devemos observar à priori três condicionantes: o grau de intensidade do 'porquê' da não aplicabilidade absoluta da Dignidade da Pessoa Humana, o segundo, seria aplicando o relativismo do interesse público sobre sua não aplicabilidade e a terceira, a justificativa concreta, trazendo fatos e dados.

Na opinião do autor, criador da Teoria dos Princípios, o mesmo acredita que a maioria dos casos da Dignidade da Pessoa Humana é relativa, uma vez 'que algo seja realizado na maior amplitude possível, consideradas as possibilidades jurídicas e de fato', adquirindo assim um caráter principiológico, com pilares basilares do princípio da adequação e proporcionalidade. Contudo, não há o descarte da parte absoluta do princípio da dignidade humana, pois há casos que há impossibilidade do seu balanceamento. 


\subsection{FÓRMULA PESO}

Em suma, quanto mais não tiver aceitação ou encaixe de um princípio, maior será a preponderância do outro princípio para atender às exigências de um caso concreto, mas para aplica-lo, o julgador deveria ter certeza que o um direito fundamental poderia ser ponderado, sendo possível por exemplo conhecer o precedente da sua origem, para que sua aplicação absoluta ou relativa não seja equivocada e venha mais a frente ser reformado pelas demais cortes.

Para isso, o Alexy norteia com a Fórmula Peso, afim de sanar dúvidas à prima facie em cortes superiores, com ampla aceitação na Alemanha e agora, trago em caso prático brasileiro sua aplicabilidade como uma possível viabilidade. Começando, devemos então ter em mente alguns pesos descritos pelo autor:

1) Peso Concreto: Relativo aos princípios que irão colidir, analisando sua intensidade, satisfação da aplicabilidade do colidente;

2) Peso Abstrato: Analise sobre uma possível anulação, regulando a superioridade de um versus outro, aqui se relativo, a dignidade humana poderia receber qualificações como leve (1) ou moderada (2), se absoluta receberia severo (4), sequência geométrica no qual leva o nome de escala triádica, equacionando os fatos apresentados como confiável, certo, plausível e não evidentemente falso.

\subsection{DIGNIDADE HUMANA POR ALEXY}

O autor em um dos seus muitos conceitos, preceitua a dignidade como algo de alta complexidade, pois a mesma possuí elementos normativos, avaliativos, descritivos e empíricos. O autor destaca o elemento descritivo como principal, pois requer autonomia descrita por Emmanuel Kant em sua teoria moral, como sendo base da dignidade da natureza humana e de toda natureza racional.

Já em sua descrição jurídica, o mesmo invoca a parte empírica, pois passa por um direito de existir e o direito de tomar decisões de qualquer tipo, ligado a uma base 
descritiva mais ampla, como o conceito de pessoa - para Alexy, para ser considerado pessoa, o humano deve atender três requisitos em conjunto: Inteligência, sentimento e consciência - e somente a partir daí teríamos a discussão inicial sobre dignidade humana.

\subsection{PRINCÍPIO DA PRÉ-EXISTÊNCIA DO CUSTEIO (Artigo 195, §5º)}

Como sabemos, esse princípio junto a universalidade estrutura e mantem todo equilíbrio financeiro da seguridade social e sem eles, seriam impossíveis o custeio pois toda criação ou aditamento deve ter base nesses dois princípios em conjunto, aqui o mesmo toma forma para Alexy como princípio e não como regra, pois na lição de Eduardo Rocha Dias e José Leandro Monteiro de Macedo ${ }^{13}$, principalmente esse o précusteio é o comezinho da boa administração pública, em consonância com o qual somente podem ser feito gastos quando previamente estabelecidos fontes de custeio.

\subsection{CASO PRÁTICO E APLICAÇÃO DA DIGNIDADE HUMANA versus PRINCÍPIO DO PRÉ-EXISTÊNCIA DO CUSTEIO}

Dona Maria, acima de 70 anos de idade foi resgatada em situação análoga a escrava (insalubre, nunca usara EPI, banheiros de lona, salários abaixo da média e 'dividas' com o senhores da fazenda), com diversos problemas de saúde, sua situação era única: perceber o auxílio doença, diante de tantas doenças ocupacionais e mais a frente aposentar-se; chegando para marcar uma perícia no INSS, a mesma recebera uma negativa, pois sua contribuição nunca foi recolhida, seu pré-custeio como ruralista e carência para perceber daquele auxílio NUNCA EXISTIU, mesmo provando um possível contrato como extratora de cana, soja e mais algumas folhas de deposito nada constava para o INSS.

Seu patrão, quando chamado à justiça, interpelado em audiência pelo julgador, afirmou que a mesma era autônoma, mas dona Maria em contrarrazões possuía um contrato de gaveta - Para fugir da situação que se encaixa no inciso $2^{\circ}$ da CLT e no rol 
de uma possível 'lista suja' seu patrão se fez de despercebido e falou que aquele contrato era de curto período de tempo, que se fosse para caracterizar, seria terceirizada e por outra firma (CNPJ) no qual ele não poderia ser passivo da ação, uma vez que o poder fiscalizatório pelo tamanho da empresa (engenho) teve que contratar uma outra "companhia" mesmo sabendo que aquele seria o trabalho fim da empresa.

O juiz, muito sábio usou uma forma de Alexy, no qual ponderou o princípio da dignidade humana, pois era nítida a situação adversa da Dona Maria e do Pré-custeio, uma vez que sua maior preocupação era conceder o auxílio a uma senhora em situação análoga que pela sua idade e estado de saúde gozavam daquele direito, não poderia abrir precedentes para algo que poderia prejudicar a previdência.

O sábio Wladimir Novaes Martinez ${ }^{14}$, entende-se de certo modo por parte do legislador aplicar um benefícios compatível com a força econômico-financeira do sistema aliando com às necessidades do indivíduo, obviamente, elegendo-se a distinção entre riscos programáveis e não programáveis, privilegiando as incapacidades em comparação a outras contingências protegíeis.

Aplicou-se então uma forma de Alexy, como peso ABSTRATO de ambos os princípios dando peso 4, o grau de INTERFERÊNCIA (cumprimento do princípio) da dignidade humana foi dado peso 4 , versus 2 para o principio do pré-custeio e no que tange a EVIDÊNCIA (menor relevância) também aplicado o peso de variação 4 na Dignidade e 2 no pré-custeio.

Com isso a Dignidade Humana superou o Pré-Custeio e a Dona Maria passou a receber o auxílio doença e espera muito em breve se aposentar.

Como solução para a Previdência não ficar descoberta, o Juiz condenou além de indenização à Dona Maria, bloqueou parte dos bens do patrão da Dona Maria, repassando parte das denúncias ao Fundo de Amparo ao Trabalhador - FAT, e as verbas previdenciárias com correção recolhidas, não exigindo assim a carência.

\subsection{CONCLUSÃO}

Revista de Direitos Sociais, Seguridade e Previdência Social | e-ISSN: 2525-9865 | Salvador | v. 4 | n. 1 | p. $18-33$ | Jan/Jun. 2018 
Com esse trabalho pude concluir que a ratio decidendi de uma ação tão complexa como essa, torna o Robert Alexy palpável à luz da justiça brasileira, os freios e contra pesos das suas variáveis nós fizeram enxergar de como o complexo fica fácil, fica claro, quando ponderamos.

A história da Dona Maria mostra que podemos confiar no judiciário brasileiro quando mostramos caminhos menos tortuosos para solucionarmos algo que nos afligem à tantos anos: Fraudes à verbas previdenciárias, dentre outras de cunho trabalhista.

Diante de uma possível reforma previdenciária, se alguns juízes pensassem como o caso Dona Maria, teríamos ganhos em escalas não só para desafogar o judiciário evitando muitas vezes recursos protelatórios, mas ganho com o principal: Arrecadação. Uma vez que afastado a carência, com o bloqueio judicial fez do custeio um mero detalhe assecuratório. Cabendo ainda uma maior fiscalização quando observamos que para assegurar a dignidade humana não basta aplicar a regra, mas observar que a vida humana obreira na verdade é o verdadeiro princípio, base e meio para alcançarmos e lutarmos pela verdadeira justiça previdenciária e trabalhista.

\subsection{REFERÊNCIAS}

2 ALEXY, ROBERT. Teoria dos Direitos Fundamentais. 5a ed., Tradução de Virgílio Afonso da Silva, São Paulo: Malheiros, 2008. Dados DIEESE; http://hdl.handle.net/10183/36707.

${ }^{3}$ SEVERO, Valdete Souto. Terceirização, Dumping Social e Direito do trabalho: Compreendendo os riscos da lógica liberal e retomando os rumos da legislação Social. São Paulo -LTR-2016

${ }^{4}$ SESSAREGO, Carlos Fernandez. Deslinde conceptual entre "daño a la persona", “daño ao proyecto de vida" e “daño moral”. Revista Foro Jurídico, año 1, n.02, Faculdad de Derecho de la Ponticia Católica del Perú, julio de 2003.

${ }^{5}$ BEBBER, Júlio Cesar. Danos Extrapatrimoniais (estético, biológico e existencial) breves considerações. Revista Ltr, vol. 73. n. 73, n. 01, Janeiro de 2009, p.28 
${ }^{6}$ NASCIMENTO. Sônia Mascaro. Dano existencial nas relações de trabalho. Revista Ltr, vol. 78, n. 08, p.965-972, agosto de 2014, passim.

${ }^{7}$ TREVISAM, Elisaide. Trabalho escravo no Brasil contemporâneo. Entre as presas da clandestinidade e as garras da exclusão. Curitiba: Juruá, 2015.

${ }^{8}$ CORTEZ, Julpiano Chaves. Trabalho escravo no contrato de emprego e os direitos fundamentais. 2. ed. São Paulo: LTr, 2014

${ }^{9}$ FLAITT, Isabela Parelli Haddad. O Trabalho escravo à luz das Convenções ns.29 e 105 da organização internacional do trabalho. In: ALVARENGA, Rúbia Zanotelli de: COLNAGO, Lorena de Mello Rezende. Direito internacional do trabalho e as convenções internacionais da OIT comentadas. São Paulo: LTR, 2014.

10 https://g1.globo.com/economia/noticia/n-de-operacoes-contra-trabalho-escravo-cai-235em-1-ano-total-de-resgatados-e-o-menor-desde-1998.ghtml

11 https://g1.globo.com/economia/noticia/lista-suja-do-trabalho-escravo-so-sera-divulgadaapos-determinacao-de-ministro-preve-portaria.ghtml

12 ALEXY, ROBERT. Dignidade Humana, Direitos Sociais e Não-positivismo inclusivo. 2015. Qualis Editora.

13 Eduardo Rocha Dias; José Leandro Monteiro de Macêdo, in Curso de Direito Previdenciário, Editora Método, 2008, página 122

${ }^{14}$ MARTINEZ, Wladimir Novaes. Princípios de Direito Previdenciário. - 5. ed. - São Paulo: LTr, 2011. p.169 